\title{
Pregnancy Outcomes following Hysteroscopic Septoplasty of Incomplete Uterine Septum
}

\author{
Ehab Mohamed Elhelw ${ }^{1}$ MD
}

\section{* Corresponding Author: \\ Ehab Mohamed Elhelw \\ Ehab.elhelw@sevoclin.com}

Received for publication October 14, 2021; Accepted Jaunary 24, 2022;

Published online Jaunary 24, 2022.

Copyright The Author published by Al-Azhar University, Faculty of Medicine, Cairo, Egypt. Users have the right to read, download, copy, distribute, print, search, or link to the full texts of articles under the following conditions: Creative Commons Attribution-Share Alike 4.0 International Public License (CC BY-SA 4.0)

doi: $10.21608 /$ aimj.2022.100485.1602

${ }^{I}$ Department of Obstetrics and Gynecology, Faculty of Medicine, Al-Azhar University, New Damietta, Egypt

\begin{abstract}
Aim of the work: The aim of this study was to evaluate pregnancy outcomes pre- and post-hysteroscopic septoplasty (HS) of the uterine septum, based on the size of the septum.

Patients and Methods: A single-center, retrospective study was conducted at Al-Azhar University Hospital, New Damietta, Egypt, over two years, from April 2018 till April 2020. The study included adult (2237 years) female patients with the incomplete uterine septum (Class Vb: partial). In all of the patients, HS and laparoscopy were done at the same time. Patients were classified into two groups; Spontaneous abortion (SA: $n=50)$ and primary infertility (PI: $n=40)$.

Result: The age of both groups was comparable (SA: $28.3 \pm 3.46$ vs. PI: $25.3 \pm 4.3$ years). Preoperatively, 50 women in the SA group had 86 pregnancies, resulting in $65(75.5 \%)$ miscarriages, 19 (22.09\%) preterm deliveries, and $2(2.32 \%)$ term deliveries. However, there was a significant difference in the results after the septum was resected. During the 24-month follow-up period after septum resection, 94 pregnancies in 90 individuals were achieved. In the PI group, 41 women had pregnancies, whereas, in the SA group, 49 women had 53 pregnancies. Conclusion: HS may enhance pregnancy outcomes in women with an incomplete uterine septum, and it should be considered in clinical practice.
\end{abstract}

Keywords: Hysteroscopic septoplasty; septate uterus; uterine septum.

Disclosure: The author has no financial interest to declare in relation to the content of this article. The Article Processing Charge was paid for by the author.

Authorship: The author has a substantial contribution to the article.

\section{INTRODUCTION}

The septate uterus (SU) is a congenital anomaly defined by the persistence of a partition in the uterus caused by a fusion defect of paramesonephric ducts during development. ${ }^{1}$ It was reported that there is a significant link between SU and many reproductive failures, including abnormal fetal presentation, intrauterine growth retardation, habitual abortion, and miscarriage. ${ }^{2}$ It is possible to have a partly septated or complete septated uterus depending on the size of the septum. In the case of an incomplete SU, the uterine cavity is separated into two distinct components, including two cervical openings and eventually a vaginal septum. ${ }^{3}$ It is challenging to detect the exact incidence of SU; however, it may reach up to 15 per 1000 population. ${ }^{4}$ The prevalence of uterine abnormalities is estimated to be around $4.3 \%$ and $3.5 \% .^{5}$ Furthermore, the SU is the most prevalent reproductive abnormality, accounting for $5.3 \% .^{6}$

In women who have had multiple abortions, premature births, and infertility, hysteroscopic septoplasty (HS) is an effective and safe surgery. ${ }^{7}$ In addition, several studies have demonstrated that HS for uterine abnormalities can improve pregnancy outcomes. ${ }^{8}$ On the other hand, because their effectiveness has not been established in welldesigned, prospective, randomized trials, postoperative hormonal treatment with estrogen and progesterone is controversial. Following surgery, estrogen and progesterone are used to stimulate endometrial development, allowing normal endometrial growth and ovulation to occur naturally. ${ }^{9}$

There is a lack of available data regarding the effectiveness of alternative treatment procedures following septum resection, despite extensive research on infertility. Therefore, the aim of this study was to evaluate pregnancy outcomes pre- and post-HS of the uterine septum, based on the size of the septum.

\section{PATIENTS AND METHODS}

\section{Study design and population}

A single-center, retrospective study was conducted at Al-Azhar University Hospital, New Damietta, Egypt, over two years from April 2018 till April 2020. The study was approved by the Institutional Review Board (IRB:00012367-21-05-008) of the Faculty of Medicine, Al-Azhar University, New Damietta, 
Egypt. Informed consent was obtained from all included patients.

\section{Inclusion and exclusion criteria}

According to the American Fertility Society classification of Mullerian duct anomalies, the study included adult (22-37 years) female patients with the incomplete uterine septum (Class $\mathrm{Vb}$ : partial). ${ }^{10}$ Patients with other causes of infertility, including the tubal factor of infertility, endometriosis, polycystic ovary syndrome, and other concomitant diseases, were excluded.

\section{Data collection}

Age, complaints, obstetric history, and postoperative pregnancy outcomes were all examined in the patients' charts. Patients were classified into two groups; Spontaneous abortion (SA: $n=50)$ and primary infertility (PI: $n=40)$. Anti-DNA antibodies, antinuclear antibodies, and anti-phospholipid antibodies were all negative. This population was not subjected to chromosomal analysis.

\section{Surgical procedure}

In all of the patients, HS and laparoscopy were done at the same time. The goal of laparoscopy was to evaluate the serosal surface of the uterus to distinguish a septate uterus from a bicornuate uterus. In addition, it was used to diagnosed other causes of infertility, including the tubal factor of infertility. Endometriosis, polycystic ovary syndrome, and other concomitant diseases were also investigated in the ovaries and abdominal cavity. This study also performed a semen analysis to assess male variables. In the early proliferative phase, all patients were admitted to the hospital and had surgery 2 to 7 days postmenstrual. Misoprostol suppository $400 \mu \mathrm{g}$ was inserted in the posterior vaginal fornix the night before surgery for simple cervical dilatation. To avoid subsequent pelvic inflammatory disease, all patients were given prophylactic antibiotics. All procedures were carried out under general anesthesia and in a very sterile environment. The surgeon utilized a cervical dilator to dilate the cervical os after administering anesthesia and placing a vaginal speculum after cleaning the external cervical os with a cotton soaked in iodine solution.

A 3.5-mm mini-hysteroscope (KARL STORZ, Germany) was used in some cases. As a factor of distending media, normal saline was employed. The pressure of uterine distention was adjusted between 110 and $150 \mathrm{~mm} \mathrm{Hg}$. An electrical resectoscope was used to confirm the size, range, and placement of the septum. A cutting current of 80 to $100 \mathrm{~W}$ was used. After examining both tubal ostia, the septa were incised with the horizontal section from the bottom edge upward until the hysteroscope could easily travel from one tubal ostium to the other, and both tubal ostia were visible. The surgeries were completed in 7 to 13 minutes by the same surgeon, who has over nine years of hysteroscopic surgery expertise.

\section{Postoperative management and follow-up}

After septoplasty, all patients had an intrauterine device put into their uterus, and they were given cyclic estrogen-progesterone treatment for three months to prevent adhesions and guarantee fast endometrial creep. Three months following the operation, the intrauterine device was removed, and a re-hysteroscopy was performed to assess the procedure's efficacy. Re-hysteroscopy was used to correct patients who had a residual portion bigger than $1 \mathrm{~cm}$. During a follow-up period, I assessed the reproductive result of each patient for whom re-hysteroscopy was done via telephone or outpatient clinic visits.

\section{Statistical Analysis}

Data were collected and then coded and analyzed using Statistical Package of Social Science (SPSS, Widnose version 22). Continuous data were presented as mean and standard deviation, while categorical data were presented as numbers and percentages.

\section{RESULTS}

The age of both groups was comparable (SA: $28.3 \pm 3.46$ vs. PI: $25.3 \pm 4.3$ years). There was no evidence of volume overload syndrome in any of the patients. None of the patients experienced uterine perforation. However, three $(3.33 \%)$ individuals required a second operation due to the presence of a residual notch bigger than $1 \mathrm{~cm}$. Preoperatively, 50 women in the SA group had 86 pregnancies, resulting in $65(75.5 \%)$ miscarriages, 19 (22.09\%) preterm deliveries, and $2(2.32 \%)$ term deliveries. However, there was a significant difference in the results after the septum was resected. During the 24month follow-up period after septum resection, 94 pregnancies in 90 individuals were achieved. In the PA group, 41 women had pregnancies, whereas, in the SA group, 49 women had 53 pregnancies. In the $\mathrm{SA}$ group, the number of miscarriages was lower after HS than before resection. Furthermore, the number of live births in the SA group was significantly greater after HS than before resection (Table 1). 


\begin{tabular}{|c|c|c|c|c|c|c|c|}
\hline & \multicolumn{2}{|c|}{ PI $(n=40)$} & \multicolumn{2}{|c|}{ SA $(n=50)$} & \multicolumn{2}{|c|}{ Total $(n=90)$} \\
\hline & & $\mathbf{n}$ & $\%$ & $\mathbf{n}$ & $\%$ & $\mathbf{n}$ & $\%$ \\
\hline \multirow{6}{*}{$\begin{array}{l}\text { Before hysteroscopic } \\
\text { septoplasty }\end{array}$} & Pregnancy & 0 & - & $50(86)$ & - & $50(86)$ & - \\
\hline & Term delivery & 0 & - & 2 & 2.32 & 2 & 2.32 \\
\hline & Preterm delivery & 0 & - & 19 & 22.09 & 19 & 22.09 \\
\hline & Miscarriage & 0 & - & 65 & 75.5 & 65 & 75.5 \\
\hline & Live birth & 0 & - & 2 & 2.32 & 2 & 2.32 \\
\hline & Ectopic pregnancy & 0 & - & 0 & 0 & 0 & 0 \\
\hline \multirow{6}{*}{$\begin{array}{l}\text { After hysteroscopic } \\
\text { septoplasty }\end{array}$} & Pregnancy & $36(41)$ & - & $49(53)$ & - & $90(94)$ & - \\
\hline & Term delivery & 32 & 78.04 & 46 & 86.79 & 78 & 82.97 \\
\hline & Preterm delivery & 2 & 4.87 & 3 & 5.66 & 5 & 5.31 \\
\hline & Miscarriage & 6 & 14.63 & 3 & 5.66 & 9 & 9.57 \\
\hline & Live birth & 33 & 80.48 & 47 & 88.67 & 80 & 85.10 \\
\hline & Ectopic pregnancy & 1 & 2.43 & 1 & 1.88 & 2 & 2.1 \\
\hline
\end{tabular}

Table 1: Comparison of the reproductive outcome before and after hysteroscopic septoplasty in patients with PI and history of SA; Data are expressed as the number of patients (number of times)

\section{DISCUSSION}

Even though there is not enough evidence that a uterine septum is linked to infertility, there is plenty of evidence that it plays a role in miscarriage, preterm labor, and other unfavorable reproductive outcomes. $^{11,12}$ The uterine septum is a common abnormality that causes poor pregnancy results; hysteroscopic septoplasty significantly improves reproductive outcomes. ${ }^{13}$ In the septal tissue, endometrial sensitivity to pre-ovulatory hormone alterations is lower than in regular uterine tissue. ${ }^{14}$ Raga et al. also noted that the number of vascular endothelial growth factor (VEGF) receptors in the transmembrane in the septal endometrium is significantly lower than in the normal uterus. ${ }^{15}$

In this study, after hysteroscopic septoplasty, there were 41 new pregnancies in the PI group, compared to no pregnancies in the preoperative period. Consequently, it has been demonstrated that hysteroscopic resection of the uterine septum is a successful and efficient treatment for women with an incomplete uterine septum and a history of infertility, resulting in a greater pregnancy rate. Furthermore, compared to before surgery, the SA group had a lower miscarriage rate and a higher live birth rate following hysteroscopic septoplasty. These results demonstrated the significant benefit of hysteroscopic septoplasty in the treatment of an incomplete uterine septum. Furthermore, many observational studies have found that hysteroscopic septoplasty is related to increased clinical pregnancy rates in women with infertility, supporting my findings. ${ }^{16,17}$ Moreover, numerous retrospective investigations have found that hysteroscopic septoplasty reduces miscarriage rates and improves reproductive outcomes. ${ }^{11,12}$ Thus, although a small number of studies have indicated that hysteroscopic septoplasty improves pregnancy outcomes, it is highly recommended in individuals who require reproductive treatment. ${ }^{18}$
Depending on the condition, the clinical efficacy of hysteroscopic septoplasty varies. For example, patients with PI might benefit from this treatment, but pregnancy rates would still be lower than those with recurrent losses. ${ }^{19}$ This suggests that numerous variables influence fertility in the group of women who have PI and that more research is needed. The impact of this technique on clinical pregnancy and miscarriage rates, on the other hand, cannot be denied.

Few studies have demonstrated that following hysteroscopic septoplasty, neither IUDs nor estrogen treatment nor both prevent intrauterine adhesions or improve pregnancy. ${ }^{20}$ Another study found that following hysteroscopic septoplasty, a 3-month estrogen with IUD insertion or estrogen alone is not required. ${ }^{21}$ My findings revealed that hysteroscopic septoplasty combined with implantation of a postoperative intrauterine device into the uterine cavity and three months of cyclic estrogen-gestagen treatment enhanced pregnancy outcomes. Another significant finding from my study is that neither group experienced future pregnancy-related uterine rupture or cervical cerclage.

This study's significance originates from its large sample size. Furthermore, data were recorded prospectively at the time of surgical treatment, and follow-up data for all patients were acquired, enhancing the generalizability of my findings. My findings revealed that hysteroscopic septoplasty could help individuals with an incomplete uterine septum enhance their reproductive function to some extent. I acknowledge that my study has some limitations, including the lack of a nonsurgical control group, which may reduce the evidentiary strength of the findings. In addition, preoperative treatment to maintain a thin endometrium, operation equipment, operating time, distention medium utilized, intraoperative bleeding, and complications were not mentioned. Because the pregnancy outcome in this cohort is 
typically favorable without surgery, the efficacy of eliminating the septum remains debatable. Only well-designed, large randomized, controlled trials can eliminate bias.

\section{CONCLUSION}

Hysteroscopic septoplasty may enhance pregnancy outcomes in women with an incomplete uterine septum and should be considered in clinical practice.

\section{REFERENCES}

1. Rikken JFW, Verhorstert KWJ, Emanuel MH, et al. Septum resection in women with a septate uterus: a cohort study. Hum Reprod. 2020; 35 (7): $1578-88$.

2. Wang Z, An J, Su Y, et al. Reproductive outcome of a complete septate uterus after hysteroscopic metroplasty. J Int Med Res [Internet]. 2020; 48(3): 030006051989383. $\underline{\text { doi/10.1177/0300060519893836 }}$

3. Guo X, Sun $X, X u$ H, et al. Successful pregnancy in each half uterus cavity of the septate uterus after transferring three embryos in one half-cavity: a case report. J Ovarian Res [Internet]. 2013;6(1):56. Available from: https://doi.org/10.1186/1757-2215-6-56

4. Wang X, Hou $\mathrm{H}$ and $\mathrm{Yu}$ Q. Fertility and pregnancy outcomes following hysteroscopic metroplasty of different sized uterine septa: A retrospective cohort study protocol. Medicine (Baltimore) [Internet]. 2019;98(30):e16623. https://pubmed.ncbi.nlm.nih.gov/31348312

5. Grimbizis GF, Camus M, Tarlatzis BC, et al. Clinical implications of uterine malformations and hysteroscopic treatment results. Hum Reprod Update. 2001;7(2):161-74.

6. Dietrich JE, Millar DM and Quint EH. Obstructive reproductive tract anomalies. $J$ Pediatr Adolesc Gynecol. 2014;27(6):396-402.

7. Roy KK, Singla S, Baruah J, et al. Reproductive outcome following hysteroscopic septal resection in patients with infertility and recurrent abortions. Arch Gynecol Obstet. 2011; 283(2):273-9.

8. Fernandes SMM, Maçães AMN, Marques AL, et al. [Reproductive outcomes after hysteroscopic septoplasty: a retrospective study]. Rev Bras Ginecol e Obstet Rev da Fed Bras das Soc Ginecol e Obstet. 2015; 37(3): $110-4$.

9. Zabak K, Bénifla JL, Uzan S. [Septate uterus and reproduction disorders: current results of hysteroscopic septoplasty]. Gynecol Obstet Fertil. 2001;29(11):829-40.

10. Hollett-Caines J, Vilos GA, Abu-Rafea B, et al. Fertility and pregnancy outcomes following hysteroscopic septum division. J Obstet
Gynaecol Canada JOGC. 2006;28(2):156-9.

11. Venetis CA, Papadopoulos SP, Campo R, et al. Clinical implications of congenital uterine anomalies: a meta-analysis of comparative studies. Reprod Biomed Online. 2014; 29(6): 665-83.

12. Tomaževič T, Ban-Frangež H, Virant-Klun I, et al. Septate, subseptate and arcuate uterus decrease pregnancy and live birth rates in IVF/ICSI. Reprod Biomed Online. 2010; 21(5): 700-5.

13. Paradisi R, Barzanti $R$, Natali $F$, et al. Hysteroscopic metroplasty: reproductive outcome in relation to septum size. Arch Gynecol Obstet. 2014; 289(3): 671-6.

14. Fedele L, Bianchi S, Marchini M, et al. Ultrastructural aspects of endometrium in infertile women with septate uterus. Fertil Steril. 1996; 65(4): 750-2.

15. Raga F, Casañ EM and Bonilla-Musoles F. Expression of vascular endothelial growth factor receptors in the endometrium of septate uterus. Fertil Steril. 2009; 92(3): 1085-90.

16. Tonguc EA, Var $\mathrm{T}$ and Batioglu $\mathrm{S}$. Hysteroscopic metroplasty in patients with a uterine septum and otherwise unexplained infertility. Int J Gynaecol Obstet Off organ Int Fed Gynaecol Obstet. 2011; 113(2):128-30.

17. Shokeir T, Abdelshaheed M, El-Shafie M, et al. Determinants of fertility and reproductive success after hysteroscopic septoplasty for women with unexplained primary infertility: a prospective analysis of 88 cases. Eur J Obstet Gynecol Reprod Biol. 2011; 155(1): 54-7.

18. Grynberg M, Gervaise A, Faivre E, et al. Treatment of twenty-two patients with complete uterine and vaginal septum. J Minim Invasive Gynecol. 2012; 19(1):34-9.

19. Bosteels J, van Wessel S, Weyers S, et al. Hysteroscopy for treating subfertility associated with suspected major uterine cavity abnormalities. Cochrane database Syst Rev [Internet]. 2018; 12(12): CD009461. https://pubmed.ncbi.nlm.nih.gov/30521679

20. Tonguc EA, Var T, Yilmaz $\mathrm{N}$, et al. Intrauterine device or estrogen treatment after hysteroscopic uterine septum resection. Int $J$ Gynecol Obstet. 2010.

21. Nawroth F, Schmidt T, Freise C, et al. Is it possible to recommend an "optimal" postoperative management after hysteroscopic metroplasty? A retrospective study with 52 infertile patients showing a septate uterus. Acta Obstet Gynecol Scand. 2002; 81(1): 55-7. 